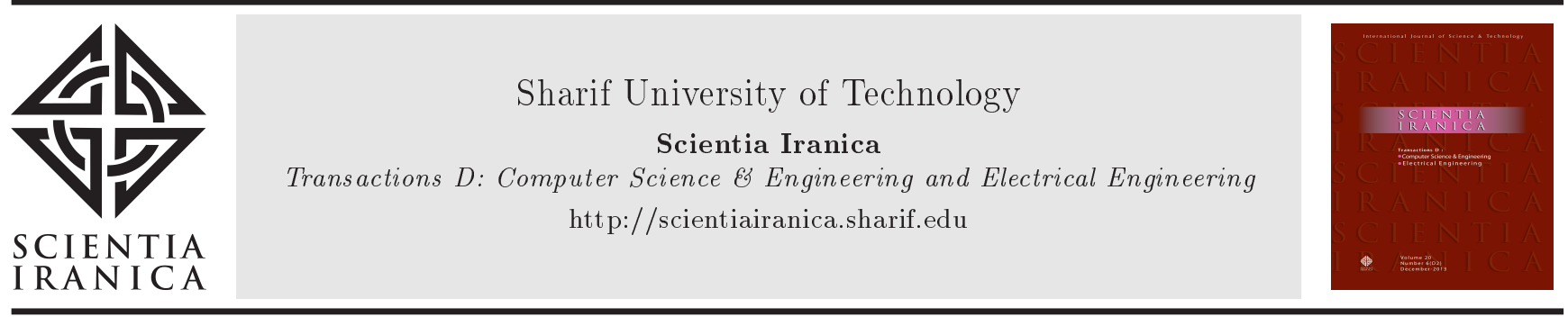

\title{
Load shifting demand response in energy scheduling based on payment cost minimization auction mechanism
}

\author{
H. Jafarirad ${ }^{\mathrm{a}}$, M. Rashidinejad ${ }^{\mathrm{b}, *}$, and A. Abdollahi ${ }^{\mathrm{b}}$ \\ a. Department of Electrical Engineering, Kerman Graduate University of Technology, Kerman, Iran. \\ b. Department of Electrical Engineering, Shahid Bahonar University of Kerman, Kerman, Iran.
}

Received 20 November 2019; received in revised form 17 August 2020; accepted 2 November 2020

KEYWORDS
Payment cost
minimization;
Load shifting demand
response;
Social welfare
maximization;
Offer cost
minimization;
Marginal pricing
scheme;
Bi-level programing.

\section{Introduction}

According to Order No. 888 issued by US Federal Energy Regulatory Commission [1], the objective of deregulation is to encourage investments to provide cheaper electric power generation by competing power producers. Under deregulation, increasing electric demand imposes unlimited market power on a few large

\footnotetext{
*. Corresponding author.

E-mail addresses: jafarirad@gmail.com (H. Jafarirad); mrashidi@uk.ac.ir (M.Rashidinejad); a.abdollahi@uk.ac.ir (A. Abdollahi)
}

doi: $10.24200 /$ sci.2020.54864.3948

\begin{abstract}
Demand Response (DR) is proven very efficacious in load mitigation, especially in peak time period. DR benefits both consumers and system operators so that they can reduce their payment and system operating cost, respectively. The proposed cost mimization is currently used as a clearing mechanism with locational marginal pricing scheme to determine consumers' payment. These clearing and pricing mechanisms are nconsistent as the system cost is minimized, but the final payments are calculated based marginal prices. Payment Cost Minimization (PCM) auction as a price-based clearing mechanism is envisaged to be an effective alternative to solve the issue. This paper demonstrates how to include DR in PCM mechanism to further reduce the consumers' payment. It facilitates utilizing price responsive consumers for Load Shifting DR (LSDR) in PCM auction. The optimization problem is modeled as a mixed-integer nonlinear bi-level programming. Duality theorem, Karush-Kuhn-Tucker conditions, and integer algebra are used to convert such a problem into a single-level mixed-integer linear programing problem. This problem is then solved by CPLEX solver in GAMS. The impacts of LSDR are studied using the proposed formulation to solve the clearing problem in the case studies, deriving promising numerical results.
\end{abstract}

(C) 2022 Sharif University of Technology. All rights reserved. power plants that typically have fossil fuel generators with fast start and ramping times, resulting in relatively large Market-Clearing Prices (MCPs) both in energy and ancillary services [2]. Offer Cost Minimization (OCM) auction mechanism, which is similar to the classical Unit Commitment (UC) in the case of inelastic demand, is currently used in most electricity markets for market clearing, while marginal pricing schemes are then usually used to determine final prices [3]. When the supply bids represent the real production costs, this type of auctions may maximize social welfare as a factual objective. Given the strategic bidding by producers to make greater benefits, this assumption does not hold in reality. Moreover, this type of auctions might be inconsistent with marginal pricing schemes 
since the total payment cost differs from minimizing the total offer costs. Therefore, consumer payments can be significantly higher than the minimized offer costs [4].

Consumer payment minimization has been proposed as a solution to the lack of incentives for suppliers to offer their actual costs. This auction mechanism directly minimizes the payment costs and is considered as an instrument to protect consumers against exercising market power by suppliers via submitting higher production bids than their actual costs [5]. From a mathematical viewpoint, the objective function of Payment Cost Minimization (PCM) is more complicated than that of OCM. The reason is the existence of MCPs in the payment terms of each consumer, leading to a self-referred optimization problem. Nonlinear terms in the objective function and constraints of PCM problem may increase its complexity. In [4], the authors proposed an augmented Lagrange Relaxation (LR) employing surrogate optimization method to solve PCM problem. Obtained results were near-optimal and some modifications should be made to guarantee the solution feasibility. Bragin et al. [6] and Chang [7] applied an almost identical optimization technique with some modifications to include the impact of transmission network. Moreover, in the literature, PCM has been addressed both with and without transmission network constraints [8]. In case of no transmission constraints, a marginal pricing scheme yields a uniform price as MCP [9]; this finding is compared with the results of OCM mechanism. Authors in [10] formulated the problem of optimization as a general bi-level programming problem, in which the resulting bi-level programming formulation was transformed into an equivalent single-level mixed integer linear programming through Karush-Kuhn-Tucker (KKT) optimality conditions through the conversion of some nonlinearity into the linear equivalent.

Considering the element of transmission network constraint makes the problem more complicated, where each bus of the network has its own Locational Marginal Price (LMP) [11]. The authors proposed a method for solving joint energy and reserved PCM auction by incorporating network security constraints. In [12], the behavior of LMP under PCM and OCM mechanisms was compared, demonstrating that the sensitivity of LMPs under the PCM mechanism was lower than that under the OCM mechanism. Some uncertainties such as load fluctuation and component unavailability were added to the main problem in [13], in which the proposed model generated a tri-level optimization problem that was solved after converting into an equivalent single-level programming problem. In another study, a PCM unit commitment model was proposed to incorporate the uncertainty associated with wind generation [14], while the optimization problem was solved using GA, where the global optimality

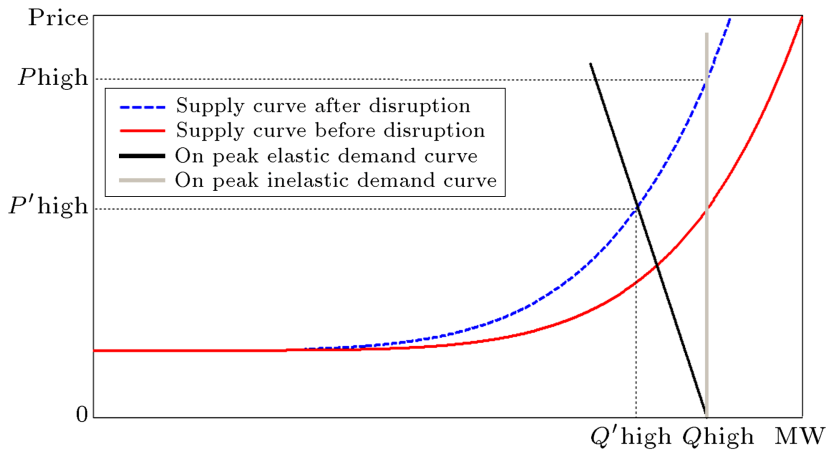

Figure 1. Demand response effect on MCP [16].

could not be guaranteed. It should be noted that none of the aforementioned studies did not consider the demand side participation in their models.

It should be noted that in the absence of demandside participation, price spikes, supply shortages, and market power may occur seriously. If retail consumers purchase electricity based on time-invariant prices, they have no incentive to respond to the wholesale prices. As shown in Figure 1, when the supply is restricted for some reasons, e.g., unexpected generation outage and/or transmission congestion, substantial reduction of price $\left(P-P^{\prime}\right)$ may take place even if a small fraction of the load $\left(Q-Q^{\prime}\right)$ responds to price variations [15].

Some studies have investigated the benefits of Demand Response (DR). In [16], an economic model based on price elasticity and consumer benefit function was introduced for analyzing incentive-based DR programs on the load curve characteristics improvement. Time-based DR in [17] and generator rescheduling as a demand side bidder in [18] were introduced as proper tools for congestion management. Emergency DR Program (EDRP) as an incentive-based DR was included in the unit commitment problem in [19]. Incorporation of Load Shifting Demand Response (LSDR) in the security constraint unit commitment problem was proposed in [20], while in [21] and [22], stochastic models of DR for reserve scheduling were discussed. A dynamic economic model of DR programs based on the concept of the flexible elasticity and the consumer benefit function was proposed in [23]. An effective mechanism for demand-side participation in electricity market is proposed as a step of utmost importance in market design, since some large consumers may have storage facilities and the ability of direct participation in the wholesale market. In this condition, they can produce and store electricity during low-price periods and may use it over high-price periods [24]. Price responsive loads were incorporated into PCM mechanism by the following studies. In [25], demand bids were considered in a two-layer structure in case no solution methodology was provided. Although some simple nonstandard pricing schemes were applied in [26] and [27], such a 
simplified pricing scheme could not be implemented in practice. It should be noted that authors in [28] pointed out the main advantage of DR, i.e., load shifting capability while it is not employed. In fact, the demand-side bids might be rejected if their values were lower than the MCPs.

Here, this study utilizes a particular type of DR, so-called LSDR. A partial LSDR is implemented in a day-ahead wholesale PCM-based electricity market. Through the application of this mechanism, the effects of the percentage of load shifting demand on the alleviated load profiles and MCP are discussed next. Given the product of MCPs and consumption levels as two continuous decision variables in association with integer decision variables, the optimization is a nonconvex problem that can be treated as a Mixed Integer Non-linear Problem (MINLP). Similar to studies in [29], a bi-level programing framework was applied here to schedule the generating units where the price responsive loads were determined at the upper level along with the unit commitment status and generation/consumption levels were specified at the lower level. Bi-level programming is fit to model such problems in which one agent, the leader, optimizes its objective function (upper-level problem) while the second agent, the follower, reacts by optimizing its own objective function (lower-level problem). These models find relevancy in these situations where the actions of the follower affect the decision-making of the leader. This is the case in price-based market clearing: The selection of accepted bids and offers (upper-level problem) depends on MCPs (lower-level problem), which are in turn determined based on the set of accepted bids and offers. MCPs at different hours are computed as the shadow prices of power balance constraints. By applying a primal-dual transformation to a mixed integer nonlinear problem that is converted to a mixed integer nonlinear problem, it is converted to a single level mixed integer nonlinear problem [30]. Bilinear terms of the single-level mixed integer nonlinear problem regarding a product of energy prices and consumption levels are linearized by use of complementary slackness of KKT optimality conditions at lower levels. In fact, a mixed integer linear problem could be solved via shelf branch and bound method, which ensured the optimality [31]. Here, a pseudo-novel approach to LSDR on a portion of forecasted load in PCM auction mechanism was proposed. Other than the load balance and capacity constraints, the intertemporal constraints of generation scheduling were also incorporated in the proposed methodology.

The remaining parts of the paper are organized as follows: Section 2 describes a load shifting model and its mathematical constraints. Section 3 presents the formulation of scheduling problem with price-sensitive demands, while Section 4 describes the proposed solu- tion methodology. Simulation studies are carried out, while numerical results and discussions are presented in Section 5. Finally, concluding remarks and possible future works are provided in Section 6 .

\section{LSDR model}

As mentioned in the introduction, the DR program employed in this paper as part of total forecasted load $\left(P_{j t}^{d}\right)$ is suitable for industrial consumers with storage facilities. The other types of loads, e.g., residential loads, are considered as inelastic loads $\left(D_{j t}^{z}\right)$, as shown by Eq. (1):

$$
D_{j t}^{\text {total }}=D_{j t}^{z}+P_{j t}^{d} .
$$

The basic concept of the proposed modeling is that this type of consumers may produce and store electricity during the low-price periods in order to meet the demand in high-price periods. Load Participation Factor (LPF) is then defined as the ratio of price responsive demand to the total demand (Eq. (2)):

$$
L P F=\frac{P_{t}^{d}}{D_{t}^{\text {total }}} .
$$

As shown in Figure 2, total load in the auction framework consists of two categories: the price taking demand and the price responsive demand. Price taking demand will receive a specified volume $\left(D_{t}^{z}\right)$ for all hours of the scheduling horizon.

The benefit of consuming demand by price taking bidders for computational reasons is taken as zero. The price responsive bid allows consumers to submit their bids for the amount of their demand that are sensitive to electricity price. Therefore, similar to generators' offer blocks, consumers' multi-segment bids have two important characteristics: benefit of consuming demand and consumption limits. Eq. (3) shows a gross surplus of price-sensitive loads based on the accepted demand side bids $\left(P_{b j t}^{d}\right)$ with respect to the marginal values that consumers submit for these bids $\left(C_{b j t}^{d}\right)$ :

$$
G S_{t}=\sum_{j} \sum_{b} C_{b j t}^{d} P_{b j t}^{d} .
$$

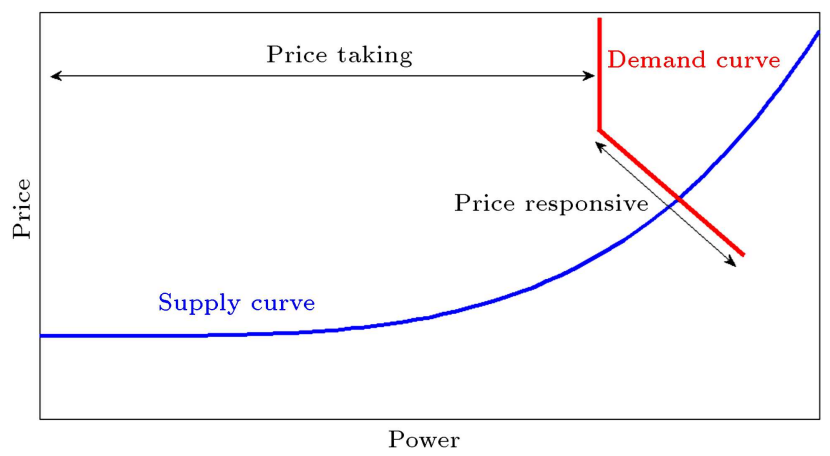

Figure 2. Price taking and price responsive demand [25]. 
In Eq. (3), $b$ is the index of a bidding block and $j$ is the index of a demand-side bidder. Total consumption level for price responsive demand $\left(P_{j t}^{d}\right)$ is provided in Eq. (4):

$$
P_{j t}^{d}=\sum_{b \in \beta_{j}} P_{b j t}^{d} .
$$

Hourly consumption limit exhibited by Eq. (5) and daily energy requirement limit shown in Eq. (6) are two constraints for the load shifting characteristics of price-sensitive demands:

$$
\begin{aligned}
& V_{j t} P_{j t \text { min }}^{d} \leq P_{j t}^{d} \leq V_{j t} P_{j t \text { max }}^{d}, \\
& 0 \leq \sum_{t} P_{j t}^{d} \leq E_{j}, \\
& 0 \leq P_{b j t}^{d} \leq P_{b j t \text { max }}^{d} .
\end{aligned}
$$

$P_{j t \text { min }}^{d}$ and $P_{j t \max }^{d}$ are the minimum and maximum amounts of active power that can be consumed during scheduling period $t$. $V_{j t}$ is the acceptance status of demand $j$ and $E_{j}$ is the maximum amount of energy that is required by bidder $j$ over the optimization horizon.

\section{PCM with LSDR problem formulation}

In this section, the mathematical formulation of the optimization problem is presented. As mentioned before, the problem is for energy scheduling of dayahead pool-based electricity market considering LSDR based on PCM auction [32]. All inter temporal constraints of generation and marginal pricing scheme except transmission constraints are modeled in this section. A bi-level programing technique is modeled based on the following mathematical statements [33].

Higher level problem:

$$
\min \sum_{t \in T}\left(\lambda_{t} D_{t}+\sum_{i \in I}\left(S U_{i t}+S D_{i t}+V_{i t} O_{i t}^{N L}\right)\right)
$$

s.t:

$$
\begin{aligned}
& S U_{i t} \geq O_{i t}^{s u}\left(V_{i t}-V_{i t-1}\right) \quad i \in I, \quad t \in T, \\
& S D_{i t} \geq O_{i t}^{s d}\left(V_{i t-1}-V_{i t}\right) \quad i \in I, \quad t \in T, \\
& \sum_{t=1}^{L_{i}}\left(1-V_{i t}\right)=0 \quad i \in I, \\
& \sum_{q=t}^{t+U T_{i}-1} V_{i q} \geq U T_{i}\left(V_{i t}-V_{i t-1}\right) \\
& i \in I, t=\left(L_{i}+1\right) \ldots\left(n_{T}-U T_{i}+1\right),
\end{aligned}
$$

$$
\begin{aligned}
& \sum_{q=t}^{n_{T}}\left(V_{i q}-\left(V_{i t}-V_{i t-1}\right)\right) \geq 0 \\
& i \in I, t=\left(n_{T}-U T_{i}+2\right) \ldots\left(n_{T}\right) \\
& L_{i}=\min \left(n_{T},\left(U T_{i}-U T_{i}^{0}\right) V_{i 0}\right) \\
& \sum_{t=1}^{F_{i}}\left(V_{i t}\right)=0 \quad i \in I \\
& \sum_{q=t}^{t+D T_{i}-1}\left(1-V_{i q}\right) \geq D T_{i}\left(V_{i t-1}-V_{i t}\right) \\
& i \in I, t=\left(F_{i}+1\right) \ldots\left(n_{T}-D T_{i}+1\right), \\
& \sum_{q=t}^{n_{T}}\left(1-V_{i q}-\left(V_{i t-1}-V_{i t}\right)\right) \geq 0 \\
& i \in I, t=\left(n_{T}-D T_{i}+2\right) \ldots\left(n_{T}\right) \\
& F_{i}=\min \left(n_{T},\left(D T_{i}-D T_{i}^{0}\right)\left(1-V_{i 0}\right),\right. \\
& V_{i t} \in(0,1) \quad i \in I, t \in T, \\
& V_{j t} \in(0,1) \quad j \in J, t \in T .
\end{aligned}
$$

The on-off status of generating units $\left(V_{i t}\right)$ and on-off status of consumers offer acceptance $\left(V_{j t}\right)$ which are the binary variables of the upper level. The startup $\left(S U_{i t}\right)$ and shut-down $\left(S D_{i t}\right)$ costs of generation unit $i$ are determined according to the offers submitted by this unit $\left(O_{i t}^{s d}, O_{i t}^{s u}\right)$ and units status following Eqs. (9)-(10). The upper level problem minimizes consumer payment and comprises two terms. The first term is the energy payment of consumers in which $\lambda_{t}$ and $D_{t}$ are continuous variables associated with hourly energy marginal price and consumption level. This term makes the problem complicated due to the bilinear product of two continuous variables. The second term is related to the start-up, shut-down, and no-load costs of generation units. These costs are fully compensated in the objective function, while minimum up- and down-time constraints are provided in Eqs. (11) and (12), respectively. The integrality constraints of binary variables are provided in Eqs. (13) and (14).

Lower level problem:

$$
\begin{aligned}
& \max \left(\sum_{t}\left(G S^{t}-O C^{t}\right)=\left(\sum_{t} \sum_{j} \sum_{b} C_{b j t}^{d} P_{b j t}^{d}\right.\right. \\
& \left.\left.\quad-\sum_{t} \sum_{i} \sum_{o} C_{o i t}^{g} P_{o i t}^{g}\right)\right),
\end{aligned}
$$

s.t.: 


$$
\begin{aligned}
& \sum_{j \in J} D_{j t}^{z}+\sum_{j \in J} P_{j t}^{d}=\sum_{i \in I} P_{i t}^{g} \quad t \in T \quad\left(\lambda_{t}\right), \\
& V_{i t} P_{i t \min }^{g} \leq P_{i t}^{g} \leq P_{i t \max }^{g} V_{i t} \\
& t \in T, \quad i \in I \quad\left(\theta_{i t}^{l o}, \theta_{i t}^{u p}\right), \\
& 0 \leq P_{\text {oit }}^{g} \leq P_{\text {oit } \max }^{g} \\
& t \in T, \quad i \in I, \quad o \in O_{i} \quad\left(\beta_{\text {oit }}^{l o}, \beta_{\text {oit }}^{u p}\right), \\
& P_{i t}^{g} \leq P_{i t-1}^{g}+R U_{i} V_{i t}-P_{i t \max }^{g}\left(1-V_{i t}\right) \\
& t \in T, \quad i \in I \quad\left(\xi_{i t}\right) \\
& P_{i t}^{g} \geq P_{i t-1}^{g}-R D_{i} V_{i t-1}-P_{i t \max }^{g}\left(1-V_{i t-1}\right) \\
& t \in T, \quad i \in I \quad\left(\delta_{i t}\right), \\
& P_{i t}^{g} \leq P_{i t \max }^{g} V_{i t+1}+R D_{i}\left(V_{i t}-V_{i t+1}\right) \\
& t=1 \cdots n_{T}-1, \quad i \in I \quad\left(\varepsilon_{i t}\right), \\
& P_{i t}^{g}=\sum_{o \in O_{i}} P_{o i t}^{g} \quad t \in T, \quad i \in I \quad\left(\gamma_{i t}\right), \\
& V_{j t} P_{j t \min }^{d} \leq P_{j t}^{d} \leq V_{j t} P_{j t \max }^{d} \\
& t \in T, \quad j \in J \quad\left(\rho_{j t}^{l o}, \rho_{j t}^{u p}\right), \\
& 0 \leq \sum_{t} P_{j t}^{d} \leq E_{j} \quad j \in J \quad\left(\alpha_{j}^{l o}, \alpha_{j}^{u p}\right), \\
& P_{j t}^{d}=\sum_{b \in \beta_{j}} P_{b j t}^{d} \quad t \in T, \quad j \in J \quad\left(\vartheta_{j t}\right), \\
& 0 \leq P_{b j t}^{d} \leq P_{b j t \max }^{d} \\
& t \in T, \quad j \in J, \quad b \in \beta_{j} \quad\left(\mu_{b j t}^{l o}, \mu_{b j t}^{u p}\right) .
\end{aligned}
$$

The lower-level objective function, Eq. (15), is considered as Social Welfare Maximization (SWM), which is the difference between consumer surplus and generation cost according to the offered bid blocks. This optimization is, in fact, a multi-period economic dispatch considering that the on/off variables $V_{i t}$ and $V_{j t}$ are supplied by the upper level optimization. Power generations $\left(P_{i t}^{g}\right)$, power consumptions $\left(P_{j t}^{d}\right)$, awarded levels of generation offer $\left(P_{\text {oit }}^{g}\right)$, and demand bidding blocks $\left(P_{b j t}^{d}\right)$ are continuous variables at this level. Generation load balance at each hour (Eq. (16)), the capacity limitations of generating units (Eq. (17)), generation limit in each offer block (Eq. (18)), rampup and start-up ramp rate (Eq. (19)), ramp-down (Eq. (20)) and shut-down ramp rate (Eq. (21)) form a list of generation-side constraints in this optimization. It is assumed that start-up and ramp-up rates are the same. The same assumption applies to ramp-down and shut-down ramp rates. Eqs. (22)-(26) describe the consumption constraints as mentioned before.

\section{Solution methodology}

In bi-level programming, any solution procedure attempting to find a global optimum must devise a system to enumerate the solution space. Such an approach cannot be taken for large-scale systems. Without such state enumeration, only the local optima can be guaranteed. In this paper, following Eq. (28), the proposed solution methodology is to convert the mixed integer nonlinear bi-level program with bilinear terms introduced in the previous section into an equivalent single-level mixed integer linear problem. To this end, the duality theorem of linear programming, integer algebra, and KKT optimality conditions are employed through the following two-step procedure.

Step 1: nonlinear single-level equivalent In the bi-level formulation of the original problem, the lower level problem is a linear programming problem because lower level problem, i.e., Eqs. (15)-(26), is parameterized in terms of the upper level binary variables. Therefore, it can be replaced by its equivalent KKT optimality conditions, where the Lagrangian function associated with the lower level is presented in Eq. (27):

$$
\begin{aligned}
& L\left(P_{i t}^{g}, P_{o i t}^{g}, P_{j t}^{d}, P_{b j t}^{d}, \lambda_{t}, \theta_{i t}^{l o}, \theta_{i t}^{u p}, \beta_{o i t}^{l o}, \beta_{o i t}^{u p},\right. \\
& \left.\xi_{i t}, \gamma_{i t}, \delta_{i t}, \varepsilon_{i t}, \vartheta_{j t}, \rho_{j t}^{l o}, \rho_{j t}^{u p}, \alpha_{j}^{l o}, \alpha_{j}^{u p}, \mu_{b j t}^{l o}, \mu_{b j t}^{u p}\right) \\
& =-\sum_{t} \sum_{j} \sum_{b} C_{b j t}^{d} P_{b j t}^{d}+\sum_{t} \sum_{i} \sum_{o} C_{o i t}^{g} P_{o i t}^{g} \\
& +\sum_{t} \lambda_{t}\left(\sum_{j} D_{j t}^{z}+\sum_{j} P_{j t}^{d}-\sum_{i} P_{i t}^{g}\right) \\
& +\sum_{t} \sum_{i}\left(\theta_{i t}^{l o}\left(-P_{i t}^{g}+V_{i t} P_{i t \min }^{g}\right)\right. \\
& \left.+\theta_{i t}^{u p}\left(P_{i t}^{g}-V_{i t} P_{i t \max }^{g}\right)\right)-\sum_{t} \sum_{i} \gamma_{i t}\left(P_{i t}^{g}\right. \\
& \left.-\sum_{o} P_{o i t}^{g}\right)+\sum_{t} \sum_{i} \sum_{o}\left(\beta_{o i t}^{u p}\left(P_{o i t}^{g}-P_{o i t \max }^{g}\right)\right. \\
& \left.-\beta_{o i t}^{l o} P_{o i t}^{g}\right)+\sum_{t} \sum_{i} \xi_{i t}\left(P_{i t}^{g}-\left(P_{i t-1}^{g}+R U_{i} V_{i t}\right.\right. \\
& \left.\left.-P_{i t \max }^{g}\left(1-V_{i t}\right)\right)\right) \\
& +\sum_{t} \sum_{i} \delta_{i t}\left(-P_{i t}^{g}+P_{i t-1}^{g}-R D_{i} V_{i t-1}\right.
\end{aligned}
$$




$$
\begin{aligned}
& \left.-P_{i t \text { max }}^{g}\left(1-V_{i t-1}\right)\right)+\sum_{t} \sum_{i} \varepsilon_{i t}\left(P_{i t}^{g}\right. \\
& \left.-\left(P_{i t \max }^{g} V_{i t+1}+R D_{i}\left(V_{i t}-V_{i t+1}\right)\right)\right) \\
& +\sum_{t} \sum_{j}\left(\rho_{j t}^{l o}\left(-P_{j t}^{d}+V_{j t} P_{j t \text { min }}^{d}\right)\right) \\
& +\sum_{t} \sum_{j} \rho_{j t}^{u p}\left(P_{j t}^{d}-V_{j t} P_{j t \max }^{d}\right) \\
& -\sum_{j}\left(\alpha_{l o}^{j} \sum_{t} P_{j t}^{d}\right)+\sum_{j}\left(\alpha_{j}^{u p}\left(\sum_{t} P_{j t}^{d}-E_{j}\right)\right) \\
& -\sum_{t} \sum_{j}\left(\vartheta_{j t}\left(P_{j t}^{d}-\sum_{b \in \beta_{j}} P_{b j t}^{d}\right)\right) \\
& +\sum_{t} \sum_{j} \sum_{b}\left(\mu_{b j t}^{u p}\left(P_{b j t}^{d}-P_{b j t \max }^{d}\right)-\mu_{b j t}^{l o} P_{b j t}^{d}\right) .
\end{aligned}
$$

Primal feasibility constraints (16)-(26), dual feasibility constraints (28)-(38), and complementary slackness conditions and KKT optimality conditions replace the lower level.

$$
\begin{aligned}
& \frac{\partial L}{\partial P_{i t}^{g}}=0 \rightarrow-\lambda_{t}-\theta_{i t}^{l o}+\theta_{i t}^{u p}-\gamma_{i t}+\xi_{i t}-\xi_{i t+1} \\
& -\delta_{i t}+\delta_{i t+1}=0 \quad t=1 \ldots n_{T}-1, \quad i \in I \\
& \frac{\partial L}{\partial P_{i t}^{g}}=0 \rightarrow-\lambda_{T}-\theta_{i T}^{l o}+\theta_{i T}^{u p}-\gamma_{i T}+\xi_{i T}-\delta_{i T}=0 \\
& t=n_{T}, \quad i \in I, \\
& \frac{\partial L}{\partial P_{j t}^{d}}=0 \rightarrow \lambda_{t}-\rho_{j t}^{l o}+\rho_{j t}^{u p}-\alpha_{j}^{l o}+\alpha_{j}^{u p}-\vartheta_{j t}=0 \\
& t \in T, \quad j \in J, \\
& \frac{\partial L}{\partial P_{o i t}^{g}}=0 \rightarrow C_{o i t}^{g}-\beta_{o i t}^{l o}+\beta_{o i t}^{u p}+\gamma_{i t}=0 \\
& t \in T, \quad i \in I, \quad o \in O_{i}, \\
& \frac{\partial L}{\partial P_{b j t}^{d}}=0 \rightarrow-C_{b j t}^{d}+\vartheta_{j t}-\mu_{b j t}^{l o}+\mu_{b j t}^{u p}=0 \\
& t \in T, \quad j \in J, \quad b \in \beta_{j}, \\
& \theta_{i t}^{l o}, \theta_{i t}^{u p} \geq 0 \quad t \in T, \quad i \in I, \\
& \beta_{o i t}^{l o}, \beta_{o i t}^{u p} \geq 0 \quad t \in T, \quad i \in I, \quad o \in O_{i}, \\
& \delta_{i t}, \xi_{i t}, \varepsilon_{i t} \geq 0, \quad t \in T, \quad i \in I, \\
& \rho_{j t}^{l o}, \rho_{j t}^{u p} \geq 0 \quad t \in T, \quad j \in J,
\end{aligned}
$$

$$
\begin{aligned}
& \alpha_{j t}^{l o}, \alpha_{j t}^{u p} \geq 0 \quad t \in T, \quad j \in J, \\
& \mu_{b j t}^{l o}, \mu_{b j t}^{u p} \geq 0 \quad t \in T, \quad j \in J, \quad b \in \beta_{j} .
\end{aligned}
$$

Based on the findings obtained in [34], linearization of complementary slackness conditions adds some more binary variables prolonging the computational time. These complementary slackness conditions help replace the nonlinear terms of the objective function applying strong duality conditions in Eq. (39):

$$
\begin{aligned}
-\sum_{t} & \sum_{j} \sum_{b} C_{b j t}^{d} P_{b j t}^{d}+\sum_{t} \sum_{i} \sum_{o} C_{o i t}^{g} P_{o i t}^{g} \\
& =\sum_{t} \lambda_{t}\left(\sum_{j} D_{j t}^{z}\right)-\sum_{t} \sum_{i}\left(\theta_{i t}^{l o}\left(V_{i t} P_{i t \min }^{g}\right)\right. \\
& \left.+\theta_{i t}^{u p}\left(-V_{i t} P_{i t \max }^{g}\right)\right) \\
& -\sum_{t} \sum_{i} \sum_{o}\left(\beta_{o i t}^{u p}\left(P_{o i t \max }^{g}\right)\right) \\
& -\sum_{t \neq 1} \sum_{i} \xi_{i t}\left(\left(R U_{i} V_{i t}-P_{i t \max }^{g}\left(1-V_{i t}\right)\right)\right) \\
& -\sum_{t \neq 1} \sum_{i} \delta_{i t}\left(R D_{i} V_{i t-1}+P_{i t \max }^{g}\left(1-V_{i t-1}\right)\right) \\
& -\sum_{t} \sum_{i} \varepsilon_{i t}\left(\left(P_{i t \max }^{g} V_{i t+1}+R D_{i}\left(V_{i t}-V_{i t+1}\right)\right)\right) \\
& +\sum_{t} \sum_{j}\left(\rho_{j t}^{l o}\left(V_{j t} P_{j t \min }^{d}\right)\right) \\
& -\sum_{t} \sum_{j} \rho_{j t}^{u p}\left(V_{j t} P_{j t \max }^{d}\right)-\sum_{j}\left(\alpha_{j}^{u p}\left(E_{j}\right)\right) \\
& -\sum_{t} \sum_{j} \sum_{b}\left(\mu_{b j t}^{u p}\left(P_{b j t \max }^{d}\right)-\mu_{b j t}^{l o} P_{b j t}^{d}\right) \\
& +\sum_{i} \delta_{i 1}\left(P_{i 0}^{g}-R D_{i} V_{i 0}-P_{i 1 \max }^{g}\left(1-V_{i 0}\right)\right) \\
+ & \sum_{i} \xi_{i 1}\left(P_{i 0}^{g}-R U_{i} V_{i t}+P_{i 1 \max }^{g}\left(1-V_{i 1}\right)\right) . \\
& (39)
\end{aligned}
$$

The resulting single-level problem is still nonlinear due to the product terms of binary variables and continuous Lagrange multipliers associated with the lowerlevel problem in the strong-duality equation. These nonlinear terms are linearized following [35] in Eq. (40):

$$
\begin{gathered}
-\sum_{t} \sum_{j} \sum_{b} C_{b j t}^{d} P_{b j t}^{d}+\sum_{t} \sum_{i} \sum_{o} C_{o i t}^{g} P_{o i t}^{g} \\
=\sum_{t} \lambda_{t}\left(\sum_{j} D_{j t}^{z}\right)
\end{gathered}
$$




$$
\begin{array}{ll}
-\sum_{t} \sum_{i}\left(a_{i t} P_{i t \min }^{g}-b_{i t} P_{i t \max }^{g}\right) & 0 \leq g_{j t} \leq \rho_{j t \max }^{l o} V_{j t}, \\
-\sum_{t} \sum_{i} \sum_{o}\left(\beta_{o i t}^{u p}\left(P_{o i t \max }^{g}\right)\right) & 0 \leq \rho_{j t}^{l o}-g_{j t} \leq\left(1-V_{j t}\right) \rho_{j t \max }^{l o}, \\
-\sum_{t \neq 1} \sum_{i}\left(c_{i t}\left(R U_{i}-P_{i t \max }^{g}\right)-\xi_{i t} P_{i t \max }^{g}\right) & 0 \leq h_{j t} \leq \rho_{j t \max }^{u p} V_{j t}, \\
& 0 \leq \rho_{j t}^{u p}-h_{j t} \leq\left(1-V_{j t}\right) \rho_{j t \max }^{u p} .
\end{array}
$$$$
-\sum_{t \neq 1} \sum_{i}\left(d_{i t}\left(R D_{i}-P_{i t \max }^{g}\right)+\delta_{i t} P_{i t \max }^{g}\right)
$$$$
-\sum_{t \neq T} \sum_{i}\left(f_{i t}\left(P_{i t \max }^{g}-R D_{i}\right)+e_{i t} R D_{i}\right)
$$$$
+\sum_{t} \sum_{j}\left(g_{i t} P_{j t \min }^{d}\right)-\sum_{t} \sum_{j}\left(h_{i t} P_{j t \max }^{d}\right)
$$$$
-\sum_{j}\left(\alpha_{j}^{u p}\left(E_{j}\right)\right)-\sum_{t} \sum_{j} \sum_{b}\left(\mu_{b j t}^{u p}\left(P_{b j t \max }^{d}\right)\right.
$$$$
\left.-\mu_{b j t}^{l o} P_{b j t}^{d}\right)
$$$$
+\sum_{i} \delta_{i 1}\left(P_{i 0}^{g}-R D_{i} V_{i 0}-P_{i 1 \max }^{g}\left(1-V_{i 0}\right)\right)
$$$$
+\sum_{i}\left(c_{i 1}\left(-R U_{i}+P_{i \max }^{g}\right)-\xi_{i 1}\left(P_{i 0}^{g}+P_{i \max }^{g}\right)\right),
$$$$
0 \leq a_{i t} \leq \theta_{i t \max }^{l o} V_{i t},
$$$$
0 \leq \theta_{i t}^{l o}-a_{i t} \leq\left(1-V_{i t}\right) \theta_{i t \max }^{l o},
$$$$
0 \leq b_{i t} \leq \theta_{i t \max }^{u p} V_{i t},
$$$$
0 \leq \theta_{i t}^{l o}-b_{i t} \leq\left(1-V_{i t}\right) \theta_{i t \max }^{u p},
$$$$
0 \leq c_{i t} \leq \xi_{i t \max } V_{i t},
$$$$
0 \leq \xi_{i t}-c_{i t} \leq\left(1-V_{i t}\right) \xi_{i t \max },
$$$$
0 \leq d_{i t} \leq \delta_{i t \max } V_{i t},
$$$$
0 \leq \delta_{i t}-d_{i t} \leq\left(1-V_{i t}\right) \delta_{i t \max },
$$$$
0 \leq e_{i t} \leq \varepsilon_{i t \max } V_{i t},
$$$$
0 \leq \varepsilon_{i t}-e_{i t} \leq\left(1-V_{i t}\right) \varepsilon_{i t \max },
$$$$
0 \leq f_{i t} \leq \varepsilon_{i t \max } V_{i t+1} \quad t \notin n_{T},
$$$$
0 \leq \varepsilon_{i t}-f_{i t} \leq\left(1-V_{i t+1}\right) \varepsilon_{i t \max } \quad t \notin n_{T},
$$

Eqs. (41)-(56) are equations of integer algebra technique used for linearization of the product of binary and continuous variables. Therefore, Eqs. (16)-(26), (28)(38), and (40)-(56) represent an equivalent mixed integer linear form for the lower-level problem. The upper bounds of dual variables are also required in order to solve this optimization. Devising a method to properly determine these parameters is of premium importance through which overestimation slows down the solution and underestimation may render the optimization infeasible. Therefore, this study uses the values of the corresponding Lagrange multipliers resulting from the optimal solution to the associated OCM problem.

Step 2: Single-level linear equivalent

Nonlinearity of the equivalent formulation lies in bilinear terms in the formulation of energy payment. A methodology based on binary expansion approach [36] and Schur's decomposition [37] were proposed for linearization of bilinear products, but such techniques are based on approximation and necessitate the inclusion of additional binary variables. This section applies the strong-duality theory of linear programming and KKT optimality condition and integer algebra for linearization of these bilinear terms. Using Eq. (30), Eqs. (57) and (58) are determined:

$$
\begin{aligned}
\sum_{t \in T} \lambda_{t} D_{t}^{\text {total }}= & \sum_{t \in T} \lambda_{t} \sum_{j \in J}\left(D_{j t}^{z}+P_{j t}^{d}\right) \\
\sum_{t} \sum_{j} \lambda_{t} P_{j t}^{d}= & \sum_{t} \sum_{j}\left(\rho_{j t}^{l o}-\rho_{j t}^{u p}+\alpha_{j}^{l o}-\alpha_{j}^{u p}\right. \\
& \left.+\vartheta_{j t}\right) P_{j t}^{d} .
\end{aligned}
$$

Using complementary slackness conditions associated with Constraints (23) and (24) at the lower level, Eqs. (59)-(62) are derived:

$$
\begin{aligned}
& \rho_{j t}^{l o}\left(P_{j t}^{d}-V_{j t} P_{j t \min }^{d}\right)=0 \rightarrow \rho_{j t}^{l o} P_{j t}^{d}=\rho_{j t}^{l o} V_{j t} P_{j t \min }^{d}, \\
& \rho_{j t}^{u p}\left(P_{j t}^{d}-V_{j t} P_{j t \max }^{d}\right)=0 \rightarrow \rho_{j t}^{u p} P_{j t}^{d}=\rho_{j t}^{u p} V_{j t} P_{j t \max }^{d}, \\
& \alpha_{j}^{l o} \sum_{t} P_{j t}^{d}=0,
\end{aligned}
$$




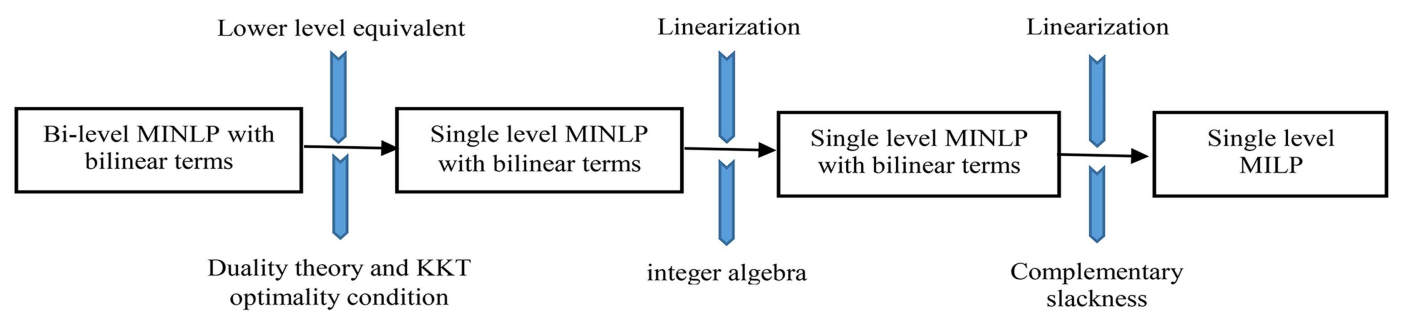

Figure 3. Solution steps flowchart.

$$
\alpha_{j}^{u p}\left(E_{j}-\sum_{t} P_{j t}^{d}\right)=0 \rightarrow \alpha_{j}^{u p} \sum_{t} P_{j t}^{d}=\alpha_{j}^{u p} E_{j}
$$

Based on Eqs. (32) and (26), Eqs. (63)-(65) are derived:

$$
\begin{gathered}
\vartheta_{j t}=C_{b j t}^{d}+\mu_{b j t}^{l o}-\mu_{b j t}^{u p}, \\
\mu_{b j t}^{l o} P_{b j t}^{d}=0 \\
\mu_{b j t}^{u p}\left(P_{b j t}^{d}-P_{b j t \max }^{d}\right)=0 \rightarrow \mu_{b j t}^{u p} P_{b j t}^{d} \\
=\mu_{b j t}^{u p} P_{b j t \max }^{d} .
\end{gathered}
$$

Using Eqs. (58)-(65), the energy payment term in Eq. (57) is expressed in Eq. (66):

$$
\begin{aligned}
\sum_{t \in T} \lambda_{t} \sum_{j \in J} & \left(D_{j t}^{z}+P_{j t}^{d}\right)=\sum_{t} \sum_{j} \lambda_{t} D_{j t}^{z} \\
& +\sum_{t} \sum_{j}\left(\rho_{j t}^{l o} V_{j t} P_{j t \min }^{d}-\rho_{j t}^{u p} V_{j t} P_{j t \max }^{d}\right) \\
& -\sum_{j} \alpha_{j}^{u p} E_{j}-\sum_{t} \sum_{j} \sum_{b} \mu_{b j t}^{u p} P_{b j t \max }^{d} \\
& +\sum_{t} \sum_{j} \sum_{b} C_{b j t}^{d} P_{b j t}^{d} .
\end{aligned}
$$

In Eq. (66), there are two nonlinear terms associated with the product terms of binary and continuous variables. These terms are linearized in Eqs. (67)-(71) using integer algebra technique:

$$
\begin{aligned}
& \sum_{t \in T} \lambda_{t} \sum_{j \in J}\left(D_{j t}^{z}+P_{j t}^{d}\right)= \\
& \quad \sum_{t} \sum_{j} \lambda_{t} D_{j t}^{z}+\sum_{t} \sum_{j}\left(k_{j t} P_{j t \min }^{d}-L_{j t} P_{j t \max }^{d}\right) \\
& \quad-\sum_{j} \alpha_{j}^{u p} E_{j}-\sum_{t} \sum_{j} \sum_{b} \mu_{b j t}^{u p} P_{b j t \max }^{d} \\
& \quad+\sum_{t} \sum_{j} \sum_{b} C_{b j t}^{d} P_{b j t}^{d}
\end{aligned}
$$

$$
\begin{aligned}
& 0 \leq k_{j t} \leq \rho_{j t \max }^{l o} V_{j t}, \\
& 0 \leq \rho_{j t}^{l o}-k_{j t} \leq\left(1-V_{j t}\right) \rho_{j t \max }^{l o}, \\
& 0 \leq L_{j t} \leq \rho_{j t \max }^{u p} V_{j t}, \\
& 0 \leq \rho_{j t}^{u p}-L_{j t} \leq\left(1-V_{j t}\right) \rho_{j t \max }^{u p} .
\end{aligned}
$$

Finally, the single-level mixed integer linear equivalent of the original bi-level nonlinear program is presented in Eq. (72):

$$
\begin{aligned}
\min & \left(\sum_{t} \sum_{j} \lambda_{t} D_{j t}^{z}+\sum_{t} \sum_{j}\left(k_{j t} P_{j t \text { min }}^{d}-L_{j t} P_{j t \max }^{d}\right)\right. \\
& -\sum_{j} \alpha_{j}^{u p} E_{j}-\left(\sum_{t} \sum_{j} \sum_{b} \mu_{b j t}^{u p} P_{b j t \max }^{d}-C_{b j t}^{d} P_{b j t}^{d}\right) \\
& \left.+\sum_{t \in T} \sum_{i \in I}\left(S U_{i t}+S D_{i t}+V_{i t} O_{i t}^{N L}\right)\right),
\end{aligned}
$$

subject to Eqs. (9)-14), (16)-(26), (28)-(38), (40)-(56), and (68)-(71).

The flowchart of all the steps is depicted in Figure 3 .

\section{Simulation studies and results analysis}

\subsection{RTS-based case}

In this section, the proposed market clearing mechanism is implemented on the 24-bus IEEE Reliability Test System (RTS) comprising 32 generating units in 24-hour load variations. The economic viability of demand shifting and its impact on market with PCM auction are evaluated. The results are also compared with those achieved by conventional SWM proposed in [24]. The effects of LSDR in comparison with price-volume biding DR model are illustrated. Data generation and all inter temporal constraints are given in Table 1.

It is assumed that generating units submit four offer blocks associated with their incremental heat rates. The hourly total forecasted system demand is shown in Table 2, in which the load profile corresponds to the Wednesday of week 35 [38]. 
Table 1. Generating units' data for RTS.

\begin{tabular}{|c|c|c|c|c|c|c|c|c|c|c|c|c|}
\hline $\begin{array}{l}\text { Unit } \\
\text { group }\end{array}$ & $\begin{array}{c}\text { Number of } \\
\text { units }\end{array}$ & $\begin{array}{l}P_{i t \text { min }}^{g} \\
(\mathrm{MW})\end{array}$ & $\begin{array}{l}P_{i t \max }^{g} \\
(\mathrm{MW})\end{array}$ & $\begin{array}{c}\boldsymbol{R} U_{i} \\
(\mathrm{MW} / \mathbf{h})\end{array}$ & $\begin{array}{c}R D_{i} \\
(\mathrm{MW} / \mathrm{h})\end{array}$ & $\begin{array}{c}U T_{i} \\
(\mathbf{h})\end{array}$ & $\begin{array}{c}D T_{i} \\
(\mathrm{~h})\end{array}$ & $\begin{array}{c}U \boldsymbol{T}_{i}{ }^{0} \\
(\mathbf{h})\end{array}$ & $\begin{array}{c}D T_{i}{ }^{0} \\
(\mathbf{h})\end{array}$ & $\begin{array}{c}O_{i t}^{s u} \\
(\$)\end{array}$ & $\begin{array}{c}O_{i t}^{s d} \\
(\$)\end{array}$ & $\begin{array}{c}O_{i t}^{N L} \\
(\$)\end{array}$ \\
\hline U12 & 5 & 2.4 & 12 & 12 & 12 & 4 & 2 & 0 & 2 & 87 & 50 & 56 \\
\hline $\mathrm{U} 20$ & 4 & 15.8 & 20 & 20 & 20 & 1 & 1 & 0 & 1 & 15 & 10 & 467 \\
\hline $\mathrm{U} 50$ & 6 & 0 & 50 & 50 & 50 & 1 & 1 & 0 & 1 & 0 & 0 & 0 \\
\hline U76 & 4 & 15.2 & 76 & 76 & 76 & 8 & 4 & 0 & 4 & 715 & 430 & 174 \\
\hline U100 & 3 & 25 & 100 & 100 & 100 & 8 & 8 & 0 & 8 & 575 & 326 & 456 \\
\hline $\mathrm{U} 155$ & 4 & 54.25 & 155 & 155 & 155 & 8 & 8 & 0 & 8 & 312 & 210 & 539 \\
\hline U197 & 3 & 68.95 & 197 & 180 & 180 & 12 & 10 & 0 & 10 & 1019 & 600 & 1324 \\
\hline $\mathrm{U} 350$ & 1 & 140 & 350 & 240 & 240 & 24 & 48 & 0 & 24 & 2298 & 950 & 1411 \\
\hline $\mathrm{U} 400$ & 2 & 100 & 400 & 400 & 400 & 1 & 1 & 0 & 1 & 0 & 0 & 531 \\
\hline
\end{tabular}

Table 2. Daily load profile.

\begin{tabular}{cccccc}
\hline period & $\begin{array}{c}\text { Forecasted } \\
\text { load (MW) }\end{array}$ & Period & $\begin{array}{c}\text { Forecasted } \\
\text { load (MW) }\end{array}$ & Period & $\begin{array}{c}\text { Forecasted } \\
\text { load (MW) }\end{array}$ \\
\hline 1 & 1277 & 9 & 1926 & 17 & 1824 \\
2 & 1257 & 10 & 2007 & 18 & 1865 \\
3 & 1216 & 11 & 2027 & 19 & 1946 \\
4 & 1176 & 12 & 2007 & 20 & 1987 \\
5 & 1196 & 13 & 1885 & 21 & 1946 \\
6 & 1318 & 14 & 1865 & 22 & 1824 \\
7 & 1459 & 15 & 1824 & 23 & 1622 \\
8 & 1723 & 16 & 1784 & 24 & 1419 \\
\hline
\end{tabular}

The demand shifting part of total load and parameters of bidding behavior are described by the following equations:

$$
\begin{aligned}
& E_{j}=\frac{L P F}{K} \sum_{t} D_{t}^{\text {total }}, \\
& P_{j t \max }^{d}=E_{j}, \\
& P_{j t \text { min }}^{d}=0 .
\end{aligned}
$$

Three bidding blocks are considered for each one of all $K$ bidders between the average and highest quantities of generating unit offer blocks as descending staircase form with a negative slope. It is assumed that all generation offers and demand bids are time invariant. The simulation was performed using a computer with $2.67 \mathrm{GHZ}$ core i5 processor with $4 \mathrm{~GB}$ of RAM using CPLEX [37] in GAMS 25.1.3 [39,40]. The results of the proposed auction mechanism are first compared with those of conventional SWM mechanism for $L P F=0$, $L P F=0.02$, and $K=10$. Figures 4 and 5 show that through the PCM auction mechanism, electricity prices at some hours are lower than those found using SWM mechanism. This leads to the reduction of consumer payment. Also, as can be seen, because of load shifting capability, some loads of peak hours are shifted to light load hours. This leads to lower electricity prices at these hours. To gain a better perspective of demand

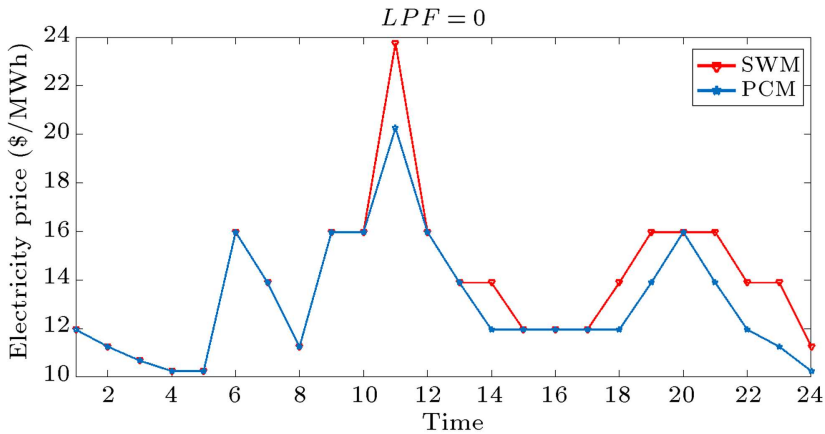

Figure 4. Electricity prices for $L P F=0$.

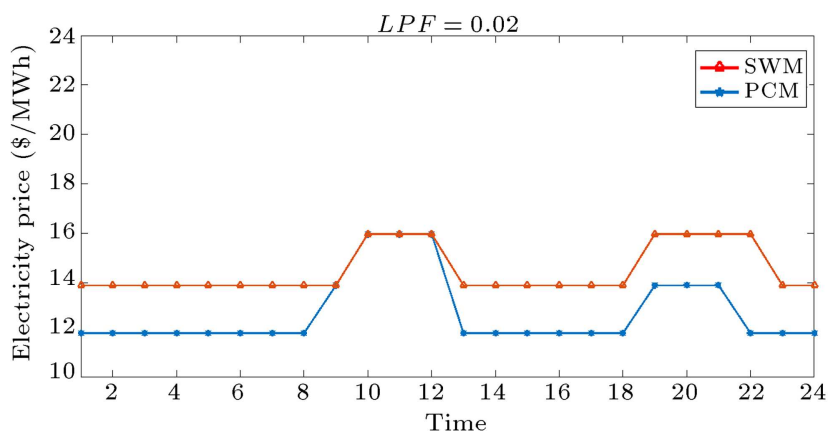

Figure 5. Electricity prices for $L P F=0.02$.

shifting effects from the economic point of view, the index of Effective Cost (EC) is used based on Eq. (76). This index represents the average marginal cost of consumers. 
Table 3. The results of PCM and SWM mechanisms.

\begin{tabular}{lcccc}
\hline & PCM with DR & SWM with DR & PCM without DR & SWM without DR \\
\hline Payment $(\$)$ & 605453 & 649308 & 633130 & 655153 \\
Social welfare $(\$)$ & -311129 & -310228 & -346561 & -345028 \\
EC $(\$ / M W h)$ & 12.91 & 14.09 & 13.53 & 14.14 \\
\hline
\end{tabular}

$$
E C=\frac{\sum_{t \in T} M C P_{t} \times\left(D_{t}^{z}+P_{t}^{d}\right)}{\sum_{t \in T}\left(D_{t}^{z}+P_{t}^{d}\right)} .
$$

Table 3 shows that at an equal consumption level, the total payments of consumers in PCM auction with DR and effective cost are $6.76 \%$ and $8.37 \%$ lower than those obtained under SWM maximization mechanism, while the social welfare is reduced by $0.29 \%$ under PCM mechanism. As mentioned before, consumers' benefit of price taking is considered zero. This leads to negative social welfare quantities.

The economic viability of the proposed auction is evaluated next at different amounts of LPFs. As can be seen in Figure 6 and 7, increasing the load participation makes the total load profile smoother. This, in turn, implies that some amount of load shifts from peak to light load periods and subsequently reduces the electrical energy price at peak load hours.

In [28], with the application of price-volume

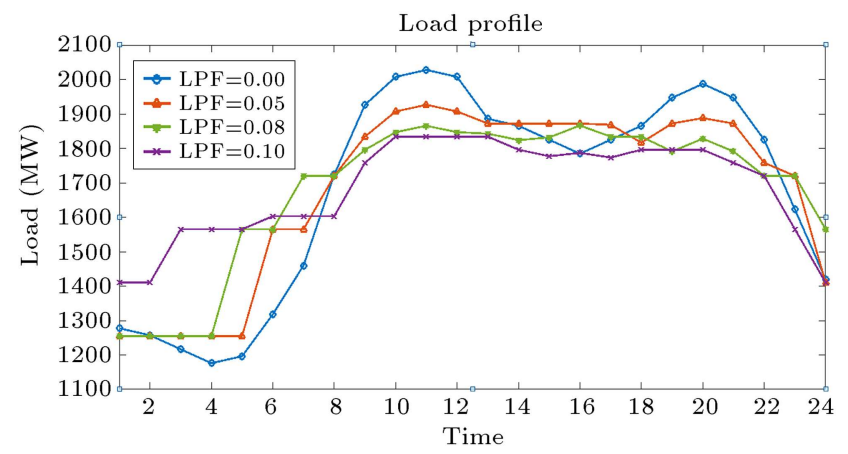

Figure 6. Load profile resulting from the proposed method with different LPF.

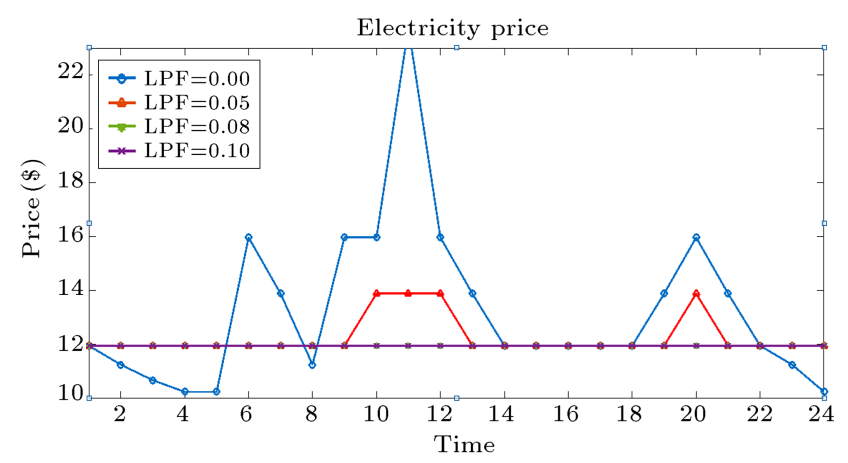

Figure 7. Electricity price resulting from the proposed method with different LPF.

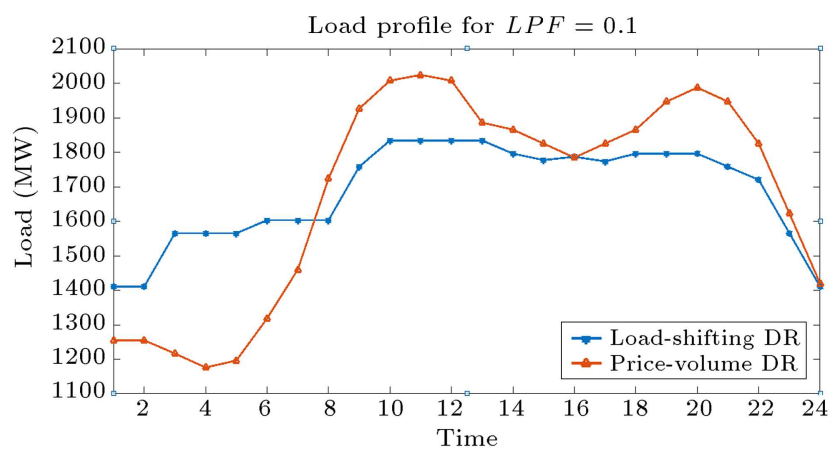

Figure 8. Load-shifting DR versus price-volume DR with PCM auction.

Table 4. Load shifting DR versus price-volume DR for $L P F=0.1$.

\begin{tabular}{lcc}
\hline & $\begin{array}{c}\text { Total daily } \\
\text { load }(\mathbf{M W})\end{array}$ & $\begin{array}{c}\text { Total consumers } \\
\text { payment(\$) }\end{array}$ \\
\hline Load-shifting DR & 40392 & 566852 \\
Price-volume DR & 40263 & 642606 \\
\hline
\end{tabular}

bidding DR, some bids were rejected and energy requirement remained unsatisfied. According to Figure 8 and Table 4, for $L P F=0.1$ in the proposed method, the total load is unchanged and equal to the total forecasted load.

It should be mentioned that at higher $L P F$ levels, some demand shifting bids may be rejected. Nevertheless, the total unsatisfied demand with the demand shifting bidding mechanism is not greater than the case with price-volume bids.

\subsection{8-Bus System}

The second case study is proposed based on the IEEE 118-bus system [41,42] and comprises 54 generating units and 91 consumers over a 24-hour timespan. Generation and load data were found in [42]. Similar to the RTS-based case, offers and bids were not modified throughout the scheduling horizon. Three-block energy offers were obtained from the linearization of the quadratic production costs. It should be noted that generation data, offers, and bids remain unchanged over the timespan. For this case study, $L P F=0.05$ and $K=91$. Table 5 provides the problem size in terms of the numbers of constraints, binary variables, and real variables.

As can be seen in Table 6, by using a stopping criterion of $0 \%$ optimality gap, the proposed approach 

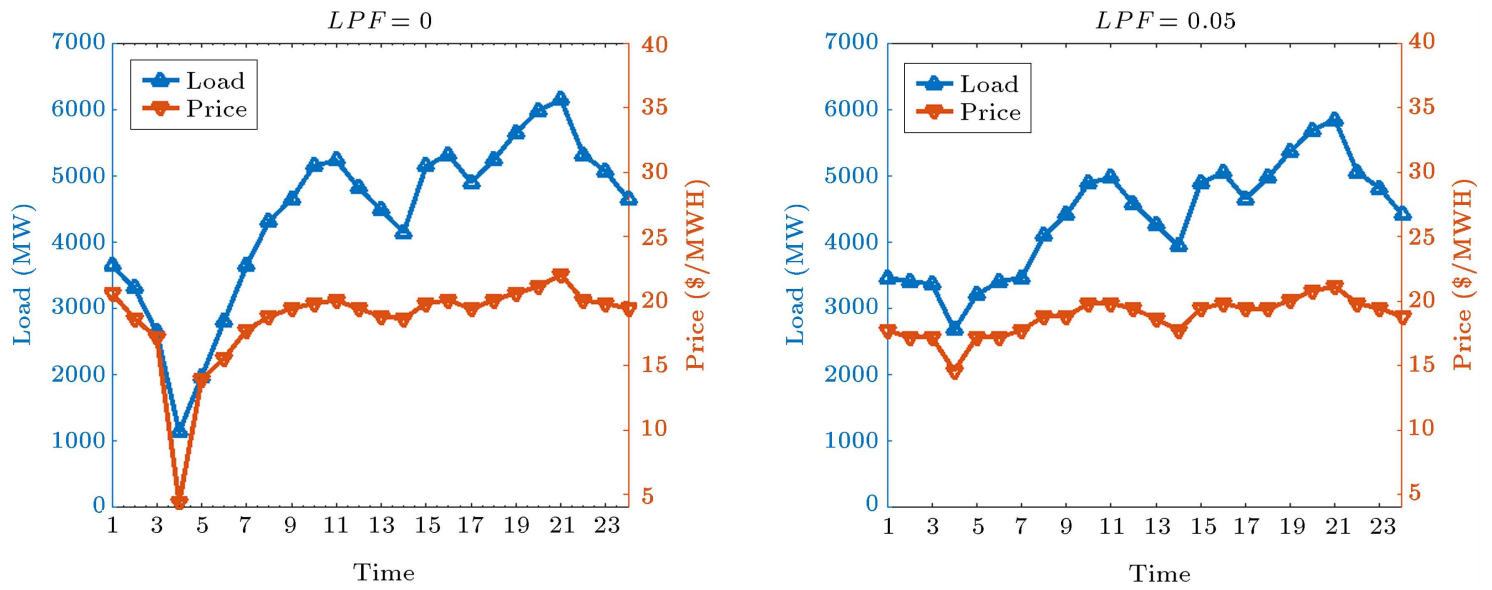

Figure 9. Market-clearing prices and system demand for 118-bus system with and without DR.
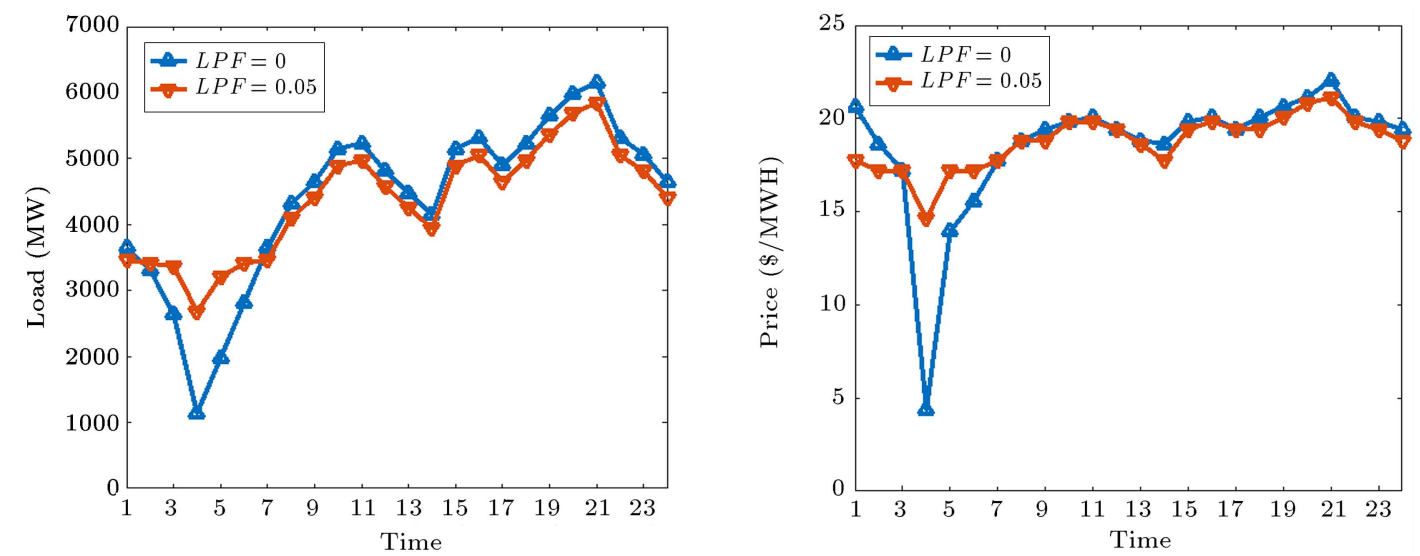

Figure 10. System demand and market-clearing prices for 118-bus system with and without DR.

Table 5. Problem dimensions.

\begin{tabular}{lccc}
\hline & $\begin{array}{c}\text { No of real } \\
\text { variables }\end{array}$ & $\begin{array}{c}\text { No of binary } \\
\text { variables }\end{array}$ & $\begin{array}{c}\text { No of } \\
\text { constraints }\end{array}$ \\
\hline 118-bus & 73107 & 3480 & 82814 \\
24-bus RTS & 26573 & 1008 & 31270 \\
case & & & \\
\hline
\end{tabular}

Table 6. Optimal solution time comparison.

\begin{tabular}{lcc}
\hline & $\begin{array}{c}\text { PCM with DR } \\
\operatorname{method}(\mathbf{s})\end{array}$ & $\begin{array}{c}\text { SWM with DR } \\
\operatorname{method}(\mathbf{s})\end{array}$ \\
\hline 118-bus & 22.32 & 1.61 \\
24-bus RTS & 46.64 & 6.18 \\
case & & \\
\hline
\end{tabular}

required $22.32 \mathrm{~s}$ to attain the optimal solution for the 118-bus case, while SWM method needed $1.61 \mathrm{~s}$. It is worth mentioning that the computing time duration required to attain such an optimal solution is shorter than that required for the RTS-based case. This is an indication of the case-dependent behavior of
Table 7. Effective cost index for 118-bus system.

\begin{tabular}{ccc}
\hline & PCM with DR & PCM without DR \\
\hline EC $(\$)$ & 19.01 & 19.38 \\
\hline
\end{tabular}

the branch-and-cut algorithm. Hourly market-clearing prices associated with and without LSDR are depicted in Figures 9 and 10 . These figures also show the hourly system demand. Note that market-clearing prices follow the shape of the demand curve based on Figure 9 .

As mentioned before, DR reduces the consumer payment as seen in Table 7 .

\section{Conclusion}

In this paper, a framework was presented to incorporate the Load Shifting Demand Response (LSDR) as part of load in the day-ahead pool-based electricity market based on consumers' payment minimization auction. The effects of such Demand Response (DR) modeling on daily load profile, total consumption of consumers, and energy prices based on Payment Cost 
Minimization (PCM) auction mechanism were analyzed. The resulting bi-level mixed integer nonlinear problem with bilinear terms was converted into a single-level mixed integer linear form and was effectively solved with zero optimality gap in an acceptable time. Compared to the previous works, the proposed modeling approach reduced the risks of consumers going unbalanced after the closure of the gate and benefited all consumers, even those that do not participate in the load shifting activities. The next step is to develop a mathematical formulation for the proposed approach considering network and revenue constraints. Further research will also be devoted to the analysis of joint energy and spinning reserve PCM markets as a crucial ancillary service.

\section{Nomenclature}

$\begin{array}{ll}\text { PCM } & \text { Payment Cost Minimization } \\ \text { OCM } & \text { Offer Cost Minimization } \\ \text { MCP } & \text { Market-Clearing Price } \\ \text { LSDR } & \text { Load Shifting Demand Response } \\ \text { EDRP } & \text { Emergency Demand Response Program } \\ \text { LPF } & \text { Load Participation Factor } \\ \text { SWM } & \text { Social Welfare Maximization }\end{array}$

\section{Indices}

$i \quad$ Generating unit

j Demand

$t \quad$ Time

$b \quad$ Demand bid block

o Generation offer block

Sets

I Generation unit indices

$J \quad$ Consumer indices

$T \quad$ Time period indices

$\beta_{j} \quad$ Demand bid block indices of consumer

$O_{i} \quad \begin{aligned} & j \\ & \text { Generation offer block indices of unit } i\end{aligned}$

\section{Continuous variables}

$\lambda_{t} \quad$ Dual variable of power balance equation

$P_{i t}^{g} \quad$ Power output of unit $i$ in period $t$

$P_{j t}^{d} \quad$ Power consumption of consumer $j$ in period $t$

$P_{\text {oit }}^{g} \quad$ Generation level awarded to unit $i$ of block $O$

$P_{b j t}^{d} \quad$ Consumption level awarded to consumer $j$ of block $b$

$S U_{i t} \quad$ Payment for the start-up of unit $i$ in period $t$
$S D_{i t} \quad$ Payment for the shut-down of unit $i$ in period $t$

$\theta_{i t}^{l o} \quad$ Dual variable of minimum power generation of unit $i$ constraint

$\theta_{i t}^{u p} \quad$ Dual variable of maximum power generation of unit $i$ constraint

$\beta_{\text {oit }}^{l o} \quad$ Dual variable of minimum power generation of unit $i$ of block $o$

$\beta_{\text {oit }}^{u p} \quad$ Dual variable of maximum power generation of unit $i$ of block $o$

\section{Constants}

$P_{i t \text { min }}^{g} \quad$ Minimum generation power

$P_{i t \max }^{g} \quad$ Maximum generation power

$P_{j t \text { min }}^{d} \quad$ Minimum consumption power

$P_{j t \max }^{d} \quad$ Maximum consumption power

$P_{b j t \max }^{d} \quad$ Maximum consumption of bidded

block

$P_{\text {oit } \max }^{g} \quad$ Maximum generation of offered block

$C_{b j t}^{d} \quad$ Price of bidded block $b$ of consumer $j$

$C_{\text {oit }}^{g} \quad$ Price of offered block $o$ of unit $i$

$R U_{i} \quad$ Ramp-up rate of unit $i$

$R D_{i} \quad$ Ramp-down rate of unit $i$

$U T_{i} \quad$ Up time of unit $i$

$D T_{i} \quad$ Down time of unit $i$

$U T_{i}^{0} \quad$ Up time of unit $i$ at end of last period

$D T_{i}^{0} \quad$ Down time of unit $i$ at end of last period

$O_{i t}^{s u} \quad$ Start up offer of unit $i$

$O_{i t}^{s d} \quad$ Shut down offer of unit $i$

$O_{i t}^{N L} \quad$ No-load offer of unit $i$

$D_{t}^{\text {total }} \quad$ Total forcasted demand

LPF Load Participation Factor

$K \quad$ Number of consumers

$E_{j} \quad$ Total energy consumption of consumer j

$n_{T} \quad$ Number of time periods

$n_{i} \quad$ Number of generating units

$n_{\beta_{j}} \quad$ Cardinality of $\beta_{j}$

$n_{o_{i}} \quad$ Cardinality of $O_{i}$

$\theta_{i t \max }^{l o} \quad$ Upper bound for $\theta_{i t}^{l o}$

$\theta_{i t \max }^{u p} \quad$ Upper bound for $\theta_{i t}^{u p}$

$\xi_{i t \max } \quad$ Upper bound for $\xi_{i t}$

$\delta_{i t \max } \quad$ Upper bound for $\delta_{i t}$

$\varepsilon_{i t \max } \quad$ Upper bound for $\varepsilon_{i t}$

$\rho_{j t \max }^{l o} \quad$ Upper bound for $\rho_{j t}^{l o}$ 
$\rho_{j t \max }^{u p} \quad$ Upper bound for $\rho_{j t}^{u p}$

$\xi_{i t} \quad$ Dual variable of ramp-up and start-up ramp rate constraint of unit $i$

$\delta_{i t} \quad$ Dual variable of ramp-down rate constraint of unit $i$

$\varepsilon_{i t}$

$\gamma_{i t}$

$\vartheta_{j t}$

$\rho_{j t}^{l o}$

$\rho_{j t}^{u p}$

$\mu_{b j t}^{l o}$

$\mu_{b j t}^{u p}$

$\alpha_{j}^{l o}$

$\alpha_{j}^{u p}$

$a_{i t}$

$b_{i t}$

$c_{i t}$

$d_{i t}$

$e_{i t}$

$f_{i t} \quad$ Auxiliary variable equal to the product $\varepsilon_{i t \max } V_{i t+1}$

$g_{i t}$

Auxiliary variable equal to the product $\rho_{j t \max }^{l o} V_{j t}$

$h_{i t} \quad$ Auxiliary variable equal to the product $\rho_{j t \text { max }}^{u p} V_{j t}$

$k_{j t} \quad$ Auxiliary variable equal to the product $\rho_{j t \text { max }}^{l o} V_{j t}$

$L_{j t} \quad$ Auxiliary variable equal to the product $\rho_{j t \max }^{u p} V_{j t}$

\section{Binary variables}

$V_{i t} \quad$ On-off statues of unit $i$ at time $t$

$V_{j t} \quad$ On-off statues of consumer $j$ offer acceptance at time $t$

\section{References}

1. U.S. Federal Energy Regulatory Commission Order No. 888, Promoting Wholesale Competition through Open Access Non-Discriminatory Transmission Services by Public Utilities; FERC: Washington, DC, USA (1996). Available online:

http://www.ferc.gov/legal/maj-ord-reg/landdocs/rm95-8-00v.txt.

2. Durvasulu, V. and Hansen, T. "Benefits of a demand response exchange participating in existing bulk-power markets", Energies, special issue on Demand Response in Electricity Markets, 11, pp. 1-3 (2018).

3. Hamian, M., Darvishan, A., Hosseinzadeh, M., et al. "A framework to expedite joint energy-reserve payment cost minimization using a custom-designed method based on mixed integer genetic algorithm", Eng. Appl. of AI, 72, pp. 203-212 (2018).

4. Luh, P.B, Blankson, W.E, Chen, Y., et al. "Payment cost minimization auction for deregulated electricity markets using surrogate optimization", IEEE Trans. Power Syst., 21(2), pp. 568-578 (2006).

5. Fernández-Blanco, R., Arroyo, J.M., and Alguacil, N. "Network-constrained day-ahead auction for consumer payment minimization", IEEE Trans. Power Syst., 29(2), pp. 526-536 (2014).

6. Bragin, M.A., Han, X., Luh, P.B., et al. "Payment cost minimization using Lagrangian relaxation and modified surrogate optimization approach", In Proc. IEEE Power Energy Soc. Gen. Meet., pp. 24-29 (2011).

7. Chang, T.S. "Comments on surrogate gradient algorithm for Lagrangian relaxation", J. Optim. Theory Appl., 137(3), pp. 691-697 (2008).

8. Vázquez, C., Rivier, M., and Pérez-Arriaga, I.J. "Production cost minimization versus consumer payment minimization in electricity pools", IEEE Trans. Power Syst., 17(1), pp. 119-127 (2002).

9. Mendes, D.P. "Resource scheduling and pricing in a centralised energy market", In Proc. 14th Power Syst. Comput. Conf., Seville, Spain, pp. 1-7 (2002).

10. Fernandez-Blanco, R., Arroyo, J.M. and Alguacil, N. "A unified bilevel programming framework for pricebased market clearing under marginal pricing", IEEE Trans. Power Syst., 27(1), pp. 517-525 (2012).

11. Nouri, A. and Hosseini, S.H. "Payment minimisation auction with security constraints", IET Gener. Transm. Distrib, pp. 1370-1380 (2017).

12. Nouri, A. and Hosseini, S.H. "Comparison of LMPs' sensitivity under payment cost minimization and offer cost minimization mechanisms", IEEE Systems Journal, 9(4), pp. 1507-1518 (2015).

13. Nouri, A., Hosseini, S.H., and Keane, A. "Stochastic network constrained payment minimization in electricity markets", IET Gener. Transm. Distrib, 13(11), pp. 2268-2279 (2019). 
14. Bizhaniaram, B. and Nouri, A. "Stochastic payment cost minimization in energy markets with high penetration of renewables", IEEE International Conference on Environment and Electrical Engineering and IEEE Industrial and Commercial Power Systems Europe (EEEIC/I\&CPS Europe), Palermo, pp. 1-4 (2018).

15. Su, C.-L. "Optimal demand-side participation in dayahead electricity markets", Ph.D. Dissertation, University Manchester, Manchester, U.K. (2007).

16. Aalami, H.A., Moghaddam, M.P., and Yousefi, G.R. "Demand response modeling considering interruptible/curtailable loads and capacity market programs", Appl. Energy, 87(1), pp. 243-250 (2010).

17. Nikzad, M., Mozafari, B., Bashirvand, M., et al. "Designing time-of-use program based on stochastic security constrained unit commitment considering reliability index", Energy, 41(1), p. 541 (2012).

18. Esmaili, M., Amjady, N., and Shayanfar, H.A. "Stochastic congestion management in power markets using efficient scenario approaches", Energy Convers. Manag., 51(11), pp. 2285-2293 (2010).

19. Rahmani-Andebili, M., Abdollahi A., and Moghaddam M.P. "An investigation of implementing emergency demand response programs (EDRP) in unit commitment problem", In Proc. IEEE PES Gen. Meeting, San Diego, CA, USA, pp. 1-7 (2011).

20. Zarei, E., Hemmatpour, M.H., and Mohammadian, M. "The effects of demand response on securityconstrained unit commitment", Scientia Iranica, Trans. D., 26(3), pp. 1627-1636 (2019). DOI: $10.24200 /$ sci.2017.4536

21. Ghahary, K., Abdollahi, A., Rashidinejad, M., et al. "Optimal reserve market clearing considering uncertain demand response using information gap decision theory", Int J Electr Power Energy Syst, 101, pp. 21322 (2018).

22. Parvania, M. and Fotuhi-Firuzabad, M. "Demand response scheduling by stochastic SCUC", IEEE Trans. Smart Grid, 1(1) pp. 89-98 (2010).

23. Abdollahi, A., Pour-Moallem, N., and Abdollahi, A. "Dynamic negawatt demand response resource modeling and prioritizing in power markets", Scientia Iranica, Trans. D., 27(3), pp. 1361-1372 (2020). DOI: $10.24200 /$ sci.2017.4406

24. Kirschen, D. and Su, C.L. "Quantifying the effect of demand response on electricity markets", IEEE Transactions on Power Systems, 24(3), pp. 1199-1207 (2009).

25. Hao, S. and Zhuang, F. "New models for integrated short-term forward electricity markets", IEEE Trans. Power Syst., 18(2), pp. 478-485 (2003).

26. Chen, Y, Luh, P.B., Yan. J.H., et al. "Payment minimization auction with demand bids and partial compensation of startup costs for deregulated electricity markets", Presented at the IEEE PES Gen. Meeting, San Francisco, CA, USA (2005).
27. Luh, P.B., Chen, Y., Blankson, W.E., et al. "Payment cost minimization with demand bids and partial capacity cost compensations for day-ahead electricity auctions", In Economic Market Design and Planning for Electric Power Systems, J. Momoh and L. Mili, Eds., Hoboken, NJ, USA: Wiley, pp. 71-85 (2010).

28. Fernández-Blanco, R., Arroyo, J.M., Alguacil, N., et al. "Incorporating price-responsive demand in energy scheduling based on consumer payment minimization", IEEE Trans. Smart Grid, 7(2), pp. 817-826 (2016)

29. Bard, J.F., Practical Bilevel Optimization: Algorithms and Applications, Norwell, MA, USA: Kluwer (1998).

30. Arroyo, J.M. "Bilevel programming applied to power system vulnerability analysis under multiple contingencies", IET Gener. Transmiss Distrib., 4(2), pp. 178-190 (2010).

31. Nemhauser, G.L. and Wolsey, L.A., Integer and Combinatorial Optimization, Hoboken, NJ, USA: Wiley (1999).

32. Zhao, F., Luh, P.B., Yan, J.H., et al. "Payment cost minimization auction for deregulated electricity markets with transmission capacity constraints", IEEE Trans. Power Syst., 23(2), pp. 532-544 (2008).

33. Fernández-Blanco, R., Arroyo, J.M., and Alguacil, N. "Network constrained day-ahead auction for consumer payment minimization", IEEE Trans. Power Syst., $\mathbf{2 9}(2)$, pp. 526-536 (2014).

34. Arroyo, J.M. "Bilevel programming applied to power system vulnerability analysis under multiple contingencies", IET Gener. Transmiss Distrib., 4(2), pp. 178-190 (2010).

35. Floudas, C.A., Nonlinear and Mixed-integer Optimization: Fundamentals and Applications, New York, NY, USA: Oxford University Press (1995).

36. Pereira, M.V., Granville, S., Fampa, M.H.C., et al. "Strategic bidding under uncertainty: A binary expansion approach", IEEE Trans. Power Syst., 20(1), pp. 180-188 (2005).

37. Horn, R.A. and Johnson, C.R., Matrix Analysis, 2nd Ed., NY, USA: Cambridge University Press (2012).

38. Grigg, C. "IEEE reliability test system", IEEE Trans. Power App. Syst., PAS-98(6), pp. 2047-2054 (1979).

39. The IBM ILOG CPLEX Website. Available: http://www-01.ibm.com/software/commerce/ optimization/cplex-optimizer

40. The GAMS Development Corporation Website [Online]. Available: http://www.gams.com (2019).

41. Power Systems Test Case Archive, Dept. Elect. Eng., University Washington, Seattle, WA, USA, (2015). [Online]. Available: http://www.ee.washington.edu/research/pstca.

42. IEEE 118-Bus System (2015) [Online]. Available: http://motor.ece.iit.edu/data/Data_118_Bus.pdf 


\section{Biographies}

Hamed Jafarirad received his BSc degree in Electrical Engineering from Shahid Bahonar University, Kerman, Iran in 2009 and MSc degree in Electrical Engineering from Power and Water University of Technology (PWUT), Tehran, Iran in 2012. He is currently pursuing the $\mathrm{PhD}$ degree at Kerman Graduate University of Technology (KGUT), Kerman, Iran. His research interests include energy management, power system optimization, and power system operation.

Masoud Rashidinejad received the BSc degree in Electrical Engineering, MSc degree in Systems Engineering from the Isfahan University of Technology, Isfahan, Iran, and PhD degree in Electrical Engineering from Brunel University, London, U.K. in 2000. He is currently a Professor at the Department of Electrical Engineering, Shahid Bahonar University of Kerman, Kerman, Iran. His research interests include the areas of power system optimization, power system planning, electricity restructuring, and energy management in smart electricity grids.

Amir Abdollahi received his BSc degree from Shahid Bahonar University, Kerman, Iran in 2007, MSc degree from Sharif University of Technology, Tehran, Iran in 2009, and $\mathrm{PhD}$ degree from Tarbiat Modarres University (TMU), Tehran, Iran in 2012, all in Electrical Engineering. He is currently an Associate Professor in the Department of the Engineering, Shahid Bahonar University of Kerman, Iran. His research interests include demand side management, optimization, planning and economics in smart grids. 